\title{
Characterization of Mortar from Church Ruins in Barangay Budiao, Daraga, Albay
}

\author{
John Carlo A. Mangay ${ }^{1}$, Eric T. Miranda ${ }^{1}$, John Mark S. Anicas ${ }^{1}$, Angel S. Recto ${ }^{2}$, Jan-Michael C. Cayme ${ }^{1}$ \\ ${ }^{1}$ School of Chemical, Biological, Materials Engineering and Sciences, Mapúa University, Muralla St., Manila, Philippines, $1002{ }^{2}$ College of Social \\ Sciences and Philosophy, Bulacan State University, Malolos, Bulacan, Philippines, 3000
}

\begin{abstract}
The lack of information about the correct ways of restoring historical masonry materials from cultural heritage structures tends to create more damage to the said structures. According to Cesare Brandi's theory of restoration, existing historical materials must be replaced with their equivalent. This paper presents the chemical composition of historical mortars acquired from church ruins of barangay Budiao, Daraga, Albay, Philippines. The historical mortar sample was characterized using petrographic analysis, sieve analysis, atomic absorption spectroscopy (AAS), thermogravimetric analysis (TGA), and infrared spectroscopy (IR). Petrographic analysis shows that the mortar sample is bounded by $90 \%$ organic material particularly coral and is held together by microcrystalline calcite (micrite) matrix that comprises of $10 \%$ of the total sample mortar composition. Sieve analysis shows a well-graded particle distribution. Atomic absorption spectroscopy (AAS) was also utilized to determine the \%Ca for each sieve fraction using $\mathrm{HCl}$ for acid digestion. TGA thermograph shows the non-linear drop in weight between $740{ }^{\circ} \mathrm{C}$ and $850{ }^{\circ} \mathrm{C}$, which corresponds to the degradation temperature of calcium carbonate or limestone. IR analysis shows essential characteristic peaks of $\mathrm{CaCO}_{3}$ at $712 \mathrm{~cm}^{-1}, 874$ $\mathrm{cm}^{-1}$, and $1437 \mathrm{~cm}^{-1}$.
\end{abstract}

\section{Introduction}

Just about two kilometers away from the bell tower of Cagsawa Church are the ruins of the town of Budiao, another place buried by the lava flow that came from Mayon Volcano, that fateful day of February 1, 1814. Only a very small section of the church protrudes above ground and on the edge of a village road. The town of Budiao gained popularity during the Spanish colonization period because it was there that the foreign colonizers set up an arena for bullfights [1]. On the other hand, historical buildings and National Cultural treasures have an important role of telling the story of what happened in the past in a certain place or society. History taken from these old buildings can be utilized as a vital source of information in numerous disciplines of arts and sciences, also historical buildings are considered to be an identity of a place or society (National Cultural Landmarks). For renovators and conservators, it is important for them to understand the characteristics and properties of the materials used in constructing these pieces of historical buildings and through understanding it, producing a compatible substitute material with the same composition as the original mortar is essential in restoration and conservation works. Furthermore, this study can be applied to other fields of disciplines like architecture, history, archeology, anthropology, etc.

The usual components of a historical mortar are composed of the following: the matrix or binder which is usually calcium carbonate from limestones, and the dispersed medium or the aggregates which is usually sand, the third component of a historical mortar comprises of the least fraction among the components is the additives, which are usually made up of clays. Lime based mortar technology were used in the Roman times until late XVIII century, it is when they replaced hydraulic binders to Portland cement as substitute binders and render, by which completely utilized in civil and military construction. By that time, the insufficient involvement in historic structures with systematic modern solutions lead to the disappearance of original renderings and finishing, which created new problems regarding compatibility issues due to the differences in mechanical and physical properties, which includes strength, porosity, permeability, color, and of course chemical composition [2].

Conservation and renovation of historical sites and buildings is a big factor in preserving a nation's history. According to Cesare Brandi's theory of compatibility, existing historical materials must be replaced with their equivalent. Hence, proper methods and materials must be used in order to preserve/restore/conserve a cultural heritage structure. Poor restoration techniques and lack of information about these construction materials are being used in the Philippines, like using Portland cement as reconstruction material to replace the original mortar and also as renderings in cultural heritage structures. 
The main focus of this study is to characterize a sample mortar acquired from the church ruins of Budiao, Daraga, Albay, which can be used as a baseline data for manufacturing a compatible substitute material for the renovation and preservation of the church ruins. Furthermore, this research provides useful analytical techniques in identifying the components of a historical mortar.

\section{Experimental Methods}

\subsection{Sampling}

Sampling is an essential process that will ensure the success of the study. The historical mortar sample was acquired in November 2016. A loose brick with its mortar still attached is where the historical mortar sample originated which will be used for later physical and chemical testing. The historical mortar samples were carefully detached from the loose brick using a stainless-steel chisel and hammer. The detached mortar samples are then placed in zip lock containers and then labelled accordingly.

\subsection{Analysis}

\subsubsection{Petrographic Analysis}

Optical microscopy of thin sections of mortar samples will be used for the petrographical-mineralogical characterization of the sample mortar's components [3]. This technique will allow to have information on the mineral constituents of the mortar sample, as well as to determine the binder matrix to the aggregates.

\subsubsection{Sieve Analysis}

Around $5.76 \mathrm{~g}$ of historical mortar sample was deliberately disaggregated and gently crushed using a ceramic mortar and pestle.To acquire information about the grain size distribution of the resulting material, sieve analysis was utilized [3], using USA Standard Testing Sieve ASTME-11 Specification, with sieve sizes of 4.75, $2.36,1.18,0.600,0.425,0.250,0.150$, and $0.075 \mathrm{~mm}$. The lowest sieve size which is on the "pan" $(<0.07 \mathrm{~mm})$ will also be considered, and each sieve fraction will be named according to the size of the sieve by which it was retained.

\subsubsection{Atomic Absorption Spectroscopy}

Atomic absorption spectroscopy allows the quantification of elemental composition of the sample mortar specifically its calcium content. Each retained sample from each sieve size were analyzed via AAS digested in hydrochloric acid $(\mathrm{HCl})$.

\subsubsection{Thermal analysis by thermogravimetric analyzer} (TGA)
A $6.50 \mathrm{mg}$ of dry, unsieved historical mortar sample was heated within the temperature range of $25^{\circ} \mathrm{C}$ to 900 ${ }^{\circ} \mathrm{C}$ at $10{ }^{\circ} \mathrm{C} /$ minute heating rate in dynamic air. The thermograph is acquired using a Mettler Toledo thermogravimetric analyzer. The weight loss of the historical mortar is plotted as the temperature increases.

\subsubsection{Infrared (IR) spectroscopy characterization}

A Thermo Scientific Nicolet 6700 FT-IR Spectrophotometer in the mid frequency region was utilized to record the infrared spectrum. A mixture of historical mortar sample and $\mathrm{KBr}$ powder were grounded and compacted to produce a transparent, thin pellet. Initially, the sample mortar was heated at $100{ }^{\circ} \mathrm{C}$ in an oven for 3 hours to guaranty that the sample is completely dry.

\section{Results and Discussion}

\subsection{Petrographic analysis}

Petrographic analysis shows closely spaced irregularly bounded organic remains, particularly coral. The internal wall structure of the bioclasts (fragments of biological origin such as shells) are poorly to moderately well preserved by a matrix of microcrystalline calcite (micritic matrix). Their internal chambers are later filled with calcite materials with slightly coarser size than micrite. Boundaries of the bioclasts are not well defined, hence the difficulty in recognizing them. Bioclasts are held together by micrite matrix. The mortar sample comprises of $90 \%$ bioclasts and $10 \%$ micritic matrix.

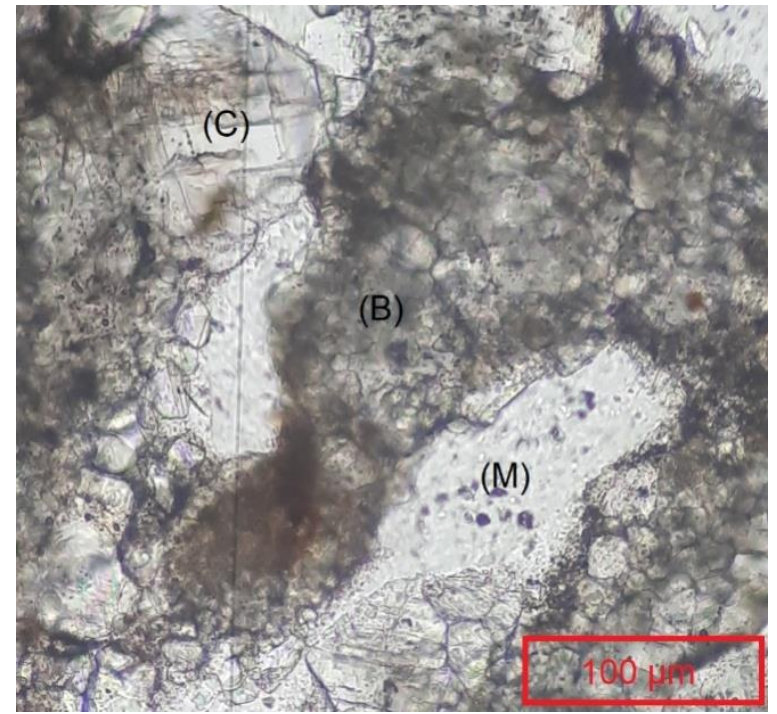

Figure 1. Mortar sample under a petrographic microscope in plane polarized light and $20 \mathrm{X}$ magnification showing calcite fragments $(\mathrm{C})$, bioclasts $(\mathrm{B})$, and micrite matrix $(\mathrm{M})$.

\subsection{Distribution of particles in the mortar}

Sieve analysis was implemented to determine the particle size distribution of the historical mortar sample. Figure 2 shows the weight percentage of each fraction that was retained in the sieve. It is observed that 4.75 
$\mathrm{mm}$ sieve retained the most weight followed by 1.18 $\mathrm{mm}, 0.6 \mathrm{~mm}$, and $2.36 \mathrm{~mm}$. Also, it was observed that some lime particles are still intact with the aggregates. The fraction that was retained in the pan $(<0.075 \mathrm{~mm})$ is correlated with the calcium carbonate binder [4].

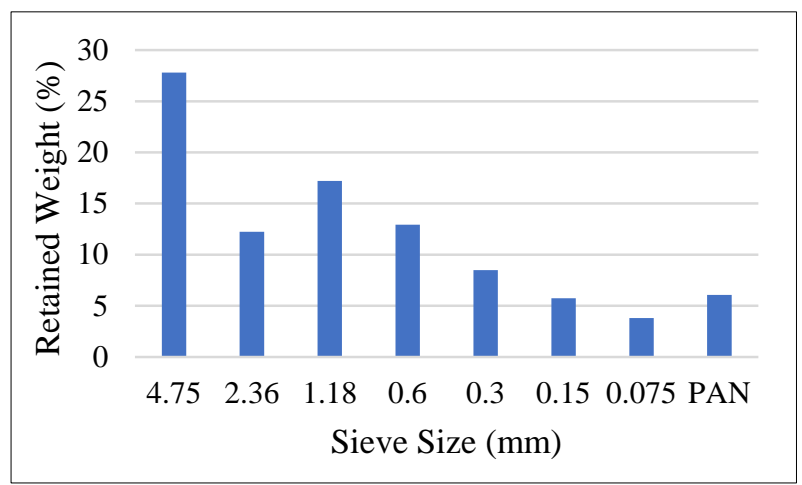

Figure 2. Weight distribution in percentage of each sieve fractions of the historical mortar sample.

It is shown in figure 3 the graph of the cumulative percentage which is also known as the percent finer $(\%$ finer) [4]. This data will signify if each sieve fractions were well represented pertaining to all sizes of the particle. The value for $D_{10}, D_{30}$, and $D_{60}$ are $0.15 \mathrm{~mm}$, $0.8 \mathrm{~mm}$, and $2.9 \mathrm{~mm}$ respectively. The values acquired were gathered via extrapolation. These values designate to the diameter (D) of the grains that pertains to the $10 \%, 30 \%$, and $60 \%$ of the sample passing through the sieve by means of weight. With these parameter values, the coefficient of curvature $\left(\mathrm{C}_{c}\right)$ was computed to be $1.47 \mathrm{~mm}$ and the coefficient of uniformity $\left(\mathrm{C}_{\mathrm{u}}\right)$ was computed equal to $19.33 \mathrm{~mm}$. With the value of $\mathrm{C}_{\mathrm{u}}$ to be greater than 4 and the value of $\mathrm{C}_{\mathrm{c}}$ is between 1 and 3 , the historical mortar sample is considered to be well graded and well represented over a wide range [5].

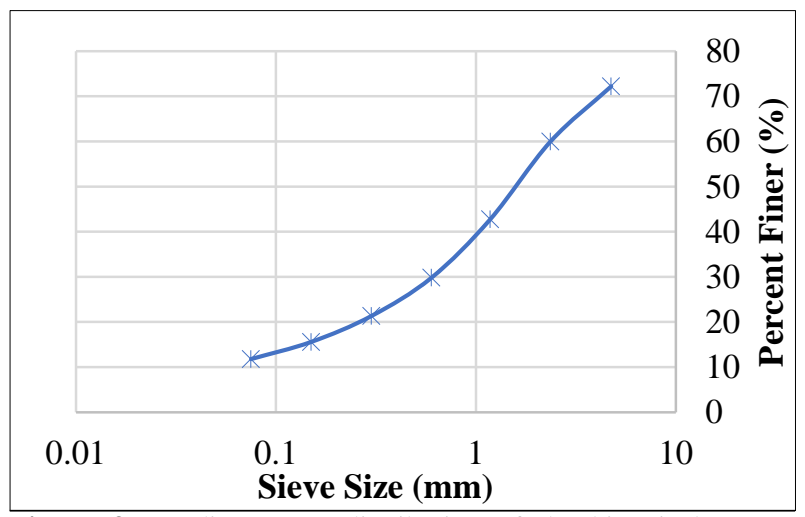

Figure 3. Grading curve distribution of the historical mortar sample.

\subsection{Atomic absorption spectroscopy (AAS)}

The sieve fractions of the historical mortar sample were digested with $\mathrm{HCl}$ to determine the distribution of calcium in sample. Taking into consideration that historical mortars are usually made from limestone $\left(\mathrm{CaCO}_{3}\right)$ which is basically the binder matrix of the historical mortar. Furthermore, the components that was digested by $\mathrm{HCl}$ solution would be considered as the binder, while the insoluble components would be the aggregates [4]. Table 1 represents the distribution of calcium content from the historical mortar sample. Looking at the $\mathrm{Ca}$ content of $4.75 \mathrm{~mm}$, it is observed that it has a lower \% $\mathrm{Ca}$ compared to calcite which is about $40 \% \mathrm{Ca}$. This pertains that during the burning process of limestones, not all $\mathrm{CaCO}_{3}$ would turn into $\mathrm{CaO}$ but instead, some $\mathrm{Ca}$ atoms would react to other components, which could be from the soil added during the process.

Table 1. Summary of the Atomic Absorption Spectroscopy (AAS) data for calcium.

\begin{tabular}{|c|c|c|}
\hline $\begin{array}{c}\text { Sieve Size } \\
(\mathbf{m m})\end{array}$ & $\begin{array}{c}\text { Mass of } \\
\text { Mortar } \\
\text { Sample (g) }\end{array}$ & $\begin{array}{c}\text { Ave. \% } \\
\text { Composition } \\
\text { of Ca }\end{array}$ \\
\hline 4.750 & 1.661 & 13.494 \\
\hline 2.360 & 0.728 & 6.149 \\
\hline 1.180 & 1.076 & 5.125 \\
\hline 0.600 & 0.822 & 4.035 \\
\hline 0.300 & 0.514 & 4.670 \\
\hline 0.150 & 0.343 & 6.939 \\
\hline 0.075 & 0.247 & 4.950 \\
\hline$<0.075$ (pan) & 0.372 & 3.506 \\
\hline
\end{tabular}

\subsection{Thermal analysis}

As the temperature was increased to $900{ }^{\circ} \mathrm{C}$, weight loss measurement of the historical mortar sample is established to acquire information about the sample's binder matrix. It is shown by the thermograph in figure 4 its continuous weight loss and its significant peaks between $740{ }^{\circ} \mathrm{C}$ and around $850{ }^{\circ} \mathrm{C}$. This particular drop in the sample's mass pertains to a characteristic peak of decomposition of calcium carbonate, with its release of $\mathrm{CO}_{2}$ [6]. The significant drop of sample's mass between $200{ }^{\circ} \mathrm{C}$ and around $590{ }^{\circ} \mathrm{C}$ is attributed to the evaporation of water which is chemically bounded to hydraulic compounds, and the decrease in weight above $590{ }^{\circ} \mathrm{C}$ is due to the loss of $\mathrm{CO}_{2}$ [7]. The first derivative plot indicates that at weight loss was highest at 801.96 ${ }^{\mathrm{o}} \mathrm{C}$.

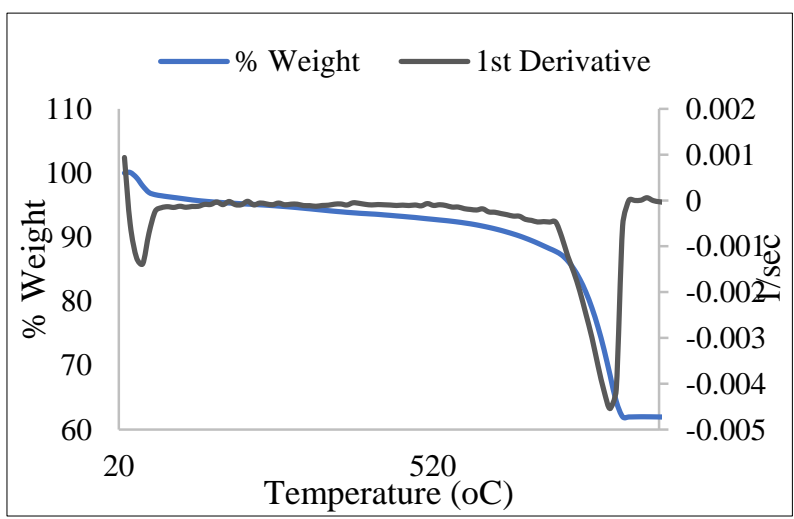

Figure 4. Thermograph of the historical mortar sample showing weight loss as temperature increases. 


\subsection{IR Spectroscopy characterization}

Shown in figure 5 is the corresponding IR absorption peaks of the inorganic materials present in the historical mortar sample. Characteristic peaks of the binder matrix which is primarily composed of $\mathrm{CaCO}_{3}$, the important absorption bands for $\mathrm{C}-\mathrm{O}$ are the out-of-plane bending (v2) at $874 \mathrm{~cm}^{-1}$, in-plane bending (v4) at 714 $\mathrm{cm}^{-1}$, and $1425 \mathrm{~cm}^{-1}$ that corresponds to the asymmetric stretching (v3) [8]. Furthermore, the broad peaks at $2511 \mathrm{~cm}^{-1}, 1155 \mathrm{~cm}^{-1}$, and $1063 \mathrm{~cm}^{-1}$ corresponds to the $\mathrm{C}-\mathrm{O}$ asymmetric stretching and is attributed to $\mathrm{CaCO}_{3}$ respectively. The presence of sand which is essentially silicon dioxide, that would pertain to the silica found in soil by which the limestone was acquired, thus absorption bands for quartz is also present. Based on the Si-O stretching peaks at $667 \mathrm{~cm}^{-1}$, and $1063 \mathrm{~cm}^{-1}$ respectively [4].

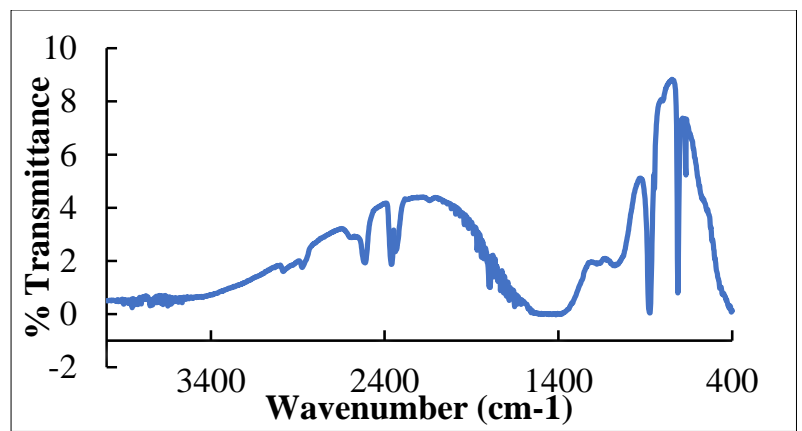

Figure 5. Mid-infrared region spectrum $\left(4000-400 \mathrm{~cm}^{-1}\right)$ of the historical mortar sample.

\section{Conclusion}

This paper presents different analytical methods which can effectively characterize historical mortars used in the Spanish-colonial period in the Philippines and can be used as a reference information for conservation and renovation of cultural heritage structures during the Spanish-Colonial period. Petrographic analysis determined the presence and majority of bioclasts which is basically fragments of shells or corals. This implies the use of shells or corals in creating the historical mortar. The majority of micritic matrix within the historical mortar sample is due to the major component of historical mortars which is limestone. The sieve analysis expressed its well-graded particle distribution. Atomic absorption spectroscopy provided the calcium content present in each sieve fractions. The acid soluble constituent is attributed to the binder (limestone) component, while the insoluble components is considered to be the aggregates. The low \%Ca $(\sim 13 \%)$ of the sample pertains to the interaction of $\mathrm{Ca}$ atoms to other constituents present in the soil were the limestone was gathered, which is basically added during the burning process of lime. Thermal analysis shows the weight loss of the historical mortar sample as the temperature increases. It was speculated that the nonlinear drop between $740{ }^{\circ} \mathrm{C}$ and $850{ }^{\circ} \mathrm{C}$ corresponds to the decomposition temperature of calcium carbonate. And lastly, IR analysis provided basic mineralogical characteristics of the historical mortar sample, primarily of $\mathrm{CaCO}_{3}$ and other constituents such as $\mathrm{SiO}_{2}$.

\section{References}

1. J. Salceda, Presentation in the $4^{\text {th }}$ Membership Meeting of PTAA and $18^{\text {th }}$ Lakbay Pilipinas.

2. A. Estevao Candeias, P. Nogueira, J. Mirao, A. Santos Silva, R. Viega, M. Gil Casal, I. Ribeiro, A.I. Seruya, "Characterization of ancient mortars: present methodology and future perspectives," Chair. of the Euro Res Coun Chem Com

3. A. Moropoulou, A. Bakolas, "Investigation of the Technology of Historic Mortars," J. Cul. Her.,1, 45-58, [2000]

4. J.M.C. Cayme, A.N. Asor. "Characterization of historical lime mortar from the Spanish colonial period in the Philippines," Con. Sci. Cul. Her., 1, 33-57, [2016]

5. R.K.W. Holtz, "An introduction to geotechnical engineering," Pren. hall, Inc. [1981]

6. J.M.C. Cayme, A.N. Asor, Jr., M.K.A.T. Alano, E.T. Miranda, "Chemical characterization of historical brickwork of the church convent in Pagsanjan, Laguna.” KIMIKA, 27, 30-41 [2016]

7. P.J.P. Gleize, E.V. Motta, D.A. Silva, H.R. Roman. Char Hist Mort Sta Cat Bzl. Cement and Concrete Composites, 31, 342-346, [2009]

8. P. Sathya, G. Velraj, S. Meyvel. Four Trans Inf Spec Stud Anc Sam Sal Reg Tam Ind. Advanced Applied Science Research, 3, 776-779, [2012] 